\title{
Uzunçayır Baraj Gölü Güncel Zooplanktonunun Bazı Su Kalite Parametreleri ile Değerlendirilmesi
}

\author{
Hilal Bulut $^{1 *}$, Ahmet Sesli², Rıdvan Tepe ${ }^{2}$ \\ ${ }^{1}$ Fırat Üniversitesi Su Ürünleri Fakültesi, Elazığ, Türkiye \\ ${ }^{2}$ Elazığ Su Ürünleri Araştırma Enstitüsü Müdürlüğü, Elazı̆̆, Türkiye

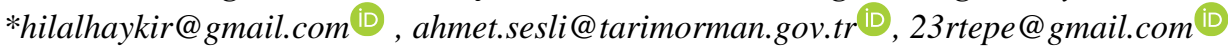 \\ Makale gönderme tarihi:24.05.2021, Makale kabul tarihi: 03.08.2021
}

\begin{abstract}
Öz
Uzunçayır Baraj Gölü'nde, Nisan 2017-Mart 2018 tarihlerinde alınan zooplankton örneklerinde 28 tür Rotifera'dan, 5 tür Cladocera'dan ve 3 tür Copepoda'dan olmak üzere toplam 36 tür teşhis edilmiştir. Asplanchna priodonta, Synchaeta oblonga, Synchaeta pectinata, Polyarthra dolichoptera en fazla kaydedilen türlerdir. Bazı su kalite parametreleri ölçülmüştür. Uzunçayır Baraj Gölünde elde edilen sonuçlara göre su sicaklığ $13,8-27,1^{\circ} \mathrm{C}, \mathrm{pH} 8,1$ 9,6, çözünmüş oksijen 6,4-12,2 mg/L, elektriksel iletkenlik 223-422 ( $\mu \mathrm{S} / \mathrm{cm})$ ve seki diski derinliği en yüksek 5,5 m olarak değişim göstermiştir.
\end{abstract}

Anahtar Kelimeler: Rotifera, Cladocera, Copepoda, bazı su kalite parametreleri

\section{The Assesment of Current Zooplankton in Uzunçayır Dam Lake with Some Water Quality Parameters}

\begin{abstract}
In the zooplankton samples taken between April 2017-March 2018 in Uzuncayir Dam Lake, a total of 36 species, 28 species from Rotifera, 5 species from Cladocera and 3 species from Copepoda, were recorded. Asplanchna priodonta, Synchaeta oblonga, Synchaeta pectinata, Polyarthra dolichoptera are the most recorded species. Some water quality parameters have been measured. The results showed that the water temperature in Uzuncayir Dam Lake was 3.8-27.10 $\mathrm{C}, \mathrm{pH}$ 8.1-9.6, dissolved oxygen 6.4-14.2 mg/ L, electrical conductivity $223-422(\mu \mathrm{S} / \mathrm{cm})$ and the secchi depth changed to the highest $5.5 \mathrm{~m}$.
\end{abstract}

Keywords: Rotifera, Clodecera, Copepoda, Some water quality parameters

\section{GİRIŞ̧}

Zooplankton su kalitesinin saptanmasinda, sucul habitatların trofik düzeyinin tespitinde ve bir alanda, evsel, endüstriyel kanalizasyon atıklarından meydana gelen, kirliliğin indikatörü olarak kullanımları dışında, bir su ekosisteminde balık, omurgasız ve ara ara da kuşların yiyeceklerini teşkil etmelerinden dolayı oldukça önemlidir (Bidder 1981; Saksena 1987; Marneffe vd. 1998; Michaloudi vd. 1997).

Farkl1 zooplankton grupları, sucul ekosistem bileşenlerini değiştiren antropojenik kaynaklı ötrofikasyona, evsel ve sanayi kaynaklı kirliliğe karşı hassas olmaları nedeniyle bu organizmaların gözlenmesi, dağılımı ve bolluğunun araştırılması sucul ekosistemler için oldukça önemlidir (Siokou-
Frangou vd. 1998; Kamburska vd. 2003; Shiganova 2005; Vidjak vd. 2006).

Sucul habitatlar birden fazla fiziksel ve kimyasal değişkenin etkisi ile karşı karşıya kalmaktadırlar. $\mathrm{Bu}$ değişkenler suda yaşayan organizmaları etkilemektedir. Plankton yaşadıkları su kaynaklarındaki ekosistemle devamlı ilişki içindedir. Plankton genel olarak suların pelajik kısmında yaşar (Gannon ve Stemberger 1978; Sladecek 1983).

Tatlı sularda ikinci besin piramadi halkasını olușturan zooplanktonik organizmalar, madde ve enerji döngüsünün sürekliliğinin sağlanmasında önemlidir. $\mathrm{Bu}$ açıdan özellikle tatlı su rezervlerindeki zooplanktonun önemli kısmını 
oluşturan rotiferlerin payı oldukça fazladır (Kaya ve Altındağ 2007). Rotiferler tatlisularda besin döngüsünde önemli bir role sahiptirler. Büyük nehir ekosistemleri içerisinde zooplanktonik türlerin sayıca fazla olduğu gösterilmiştir. (Wallace ve Snell 1991).

$\mathrm{Bu}$ araştırmanın amacı, Uzunçayır Baraj Gölü'nde güncel zooplankton faunasını belirlemenin yanı sıra yıllık değişiklikleri tanımlamak ve gölün geçmiş yıllardaki durumu ile mukayese yapabilmek, sonuçları önceki çalışmaların sonuçlarıyla karşılaştırmaktır. Bu bölgede daha önce farklı su kaynakları da dahil olmak üzere yapılmış çeşitli çalışmalar mevcuttur (Çoban vd. 2013; ; Saler vd. 2014; Erkil vd.2015; Özcan 2019; Özcan 2020).

\section{MATERYAL VE METOT}

\section{Çalışma Alanı}

Uzunçayır Baraj1, Tunceli'de Munzur Suyu üzerinde, 1996 ile 2003 tarihleri arasında yapılmış olup enerji üretmek maksadıyla kurulmuş bir barajdır. Kaya gövde dolgu tipinde olan, baraj $551.000 \mathrm{~m}^{3}$ gövde hacmine sahip olup $70,00 \mathrm{~m}$ akarsu yatağından yüksekliği, göl hacmi normal su kotunda $308,00 \mathrm{hm}^{3}$, normal su kotunda göl alanı $13,43 \mathrm{~km}^{2}$ dir (DSİ 2021). İstasyonların seçimi için ana giriş kısım, orta kısım, ana mansabın arka kısmı ve barajdan sonraki çıkış kısmı olacak şekilde örneklemeler yapılmıştır (Şekil 1).

$\mathrm{Bu}$ barajin faaliyete girmesiyle beraber buraya gelen kirleticilerin (kayaçlardan yıkanan elementler, sızıntı suyu yani ilin düzensiz katı atık sahasından kaynaklanan, evsel sıv1 atık vs.,) neden olduğu kirlilik neticesinde bu baraj gölünün su kalite değerlerinde olumsuzluklara sebep olabilmektedir. Ayrıca yeni şehirleşme hareketliliği baraj göl çevresinde başlamıştır. Bu nedenle 2012 de Tunceli Belediyesi bünyesi dahilinde faaliyete geçmiş olan kentsel atıksu arıtma tesisi bulunmaktadır (Boztuğ vd. 2012).

\section{Bazı Fiziksel ve Kimyasal Parametrelerin Ölçümü}

Uzunçayır Baraj Gölü'nün bazı fiziksel, kimyasal parametreleri ile biyolojik özelliklerini incelemek için çalışma süresince her ay arazide ölçümler kaydedilmiştir. Sicaklık, çözünmüş oksijen ve pH değerleri ve elektriksel iletkenlik çalışma boyunca her numune alımında anında arazide ölçülmüştür. Elektriksel iletkenlik, çözünmüş oksijen, sıcaklık ve
pH istasyon noktalarında YSI 6600 V2 model ölçüm aleti ile 1 şı geçirgenliği ise Secchi diski ile örnekleme alanında ölçülmüștür

\section{Zooplankton Örneklerinin Alınması ve Teşhis Edilmesi}

Uzunçayır Baraj Gölü zooplanktonunu tespit edip güncel faunayı oluşturmak maksadiyla Nisan 2017-Mart 2018 tarihleri arasinda aylık numuneler alınmıştır. Göz açıklığı $55 \mu$ olan plankton ağıyla 5 'er defa numune alınıp 250 ml'lik kavanozlara konularak en kısa zamanda laboratuara getirilmiştir. Örnekler \% 4'lük formaldehite konulup muhafaza edilmiştir. Zooplankton numuneleri Leitz marka inverted mikroskop altında incelenerek ve ilgili kaynaklardan (Edmondson 1959; Grasse 1965; Kolisko 1974; Koste 1978a, 1978b; Dumont ve De Ridder 1987; Negrea 1983; Einsle 1996) faydalanılarak Rotifera, Cladocera ve Copepoda'nın tür teşhisi yapılmıştır.Herhangi deformasyon olması ihtimaline karşı geçici preparat hazırlanırken, zooplanktonun teşhisini doğru yapabilmek için kalıcı preparatlar hazırlanmıştır.

\section{TARTIŞMA VE SONUÇ}

Uzunçayır Barajında Rotifera'dan 28, Cladocera'dan 5 ve Copepoda'dan 3 tür olmak üzere toplamda 36 tür teşhis edilmiştir. Türlerin isimleri aşağıda sıralanmıștır. Baraj gölünden kaydedilen zooplankton türlerinin aylık dağılımları tablolar halinde verilmiştir (Tablo 1-4).

\section{Rotifera}

Ascomorpha ecuadis Petry, 1850

Ascomorpha saltans Bartsch, 1870

Asplanchna priodonta Gosse, 1850

Asplanchna sieboldi (Leydig, 1854)

Asplanchna girodi de Guerne, 1888

Cephalodella gibba (Ehrenberg, 1830)

Colurella colurus (Ehrenberg, 1830)

Euchlanis dilatata Ehrenberg, 1832

Filinia longiseta (Ehrenberg, 1834)

Filinia terminalis (Plate, 1886)

Gastropus stylifer (Imhof, 1891)

Keratella cochlearis (Gosse, 1851)

Keratella quadrata (Müller, 1786)

Lecane furcata (Murray, 1913)

Lecane luna (Müller, 1776)

Lecane lunaris (Ehrenberg, 1832)

Lecane stenroosi (Meissner, 1908)

Lepadella ovalis (Müller, 1786) 
Notholca acuminata (Ehrenberg, 1832)

Notholca squamula (Müller, 1786)

Notommata glyphura Wulfert, 1935

Polyarthra dolichoptera Idelson,1925

Proales decipiens (Ehrenberg, 1832)

Synchaeta oblonga Ehrenberg, 1832

Synchaeta pectinata Ehrenberg, 1832

Trichocerca capucina (Wierzejski \&

Zacharias, 1893)

Trichocerca similis (Wierzeski, 1893)

Trichotria tetractis (Ehrenberg, 1830)

\section{Cladocera}

Alona guttata Sars, 1862

Bosmina longirostris (O.F.Müller, 1785)

Chydorus sphaericus (O.F.Müller, 1776)

Daphnia cucullata Sars, 1862

Moina macrocopa (Straus, 1820)

\section{Copepoda}

Acanthodiaptomus denticornis (Wierzejski, 1887)

Acanthocyclops robustus (G.O.Sars, 1863)

Cyclops vicinus Uljanin, 1875

1.istasyonda kaydedilen türlerden en önemlisi

Rotifera'dan A. priodonta ve S. pectinata olmuştur. Her iki tür de 8 ay boyunca kaydedilmiştir. Bu türü takip eden ve 5 ay ortaya çıkan tür $K$. cochlearis olmuştur. Cladocera dan ise B. longirostris ve D. cucullata Ekim ayında gözlemlenmiş olup başka bir türe rastlanılmamıştır. Copepoda'dan ise A. robustus en sik gözlemlenen organizma olmuştur (Tablo 1).

2.istasyonda kaydedilen türlerden en önemlisi Rotifera'dan $P$. dolichoptera olmuştur. Tür 8 ay boyunca tespit edilmiştir. Bu türü 6 ay ortaya çıkan $K$. cochlearis takip etmiştir. Cladocera'dan ise $B$. longirostris olup Copepoda'dan ise A. denticornis ve C. vicinus' tan başka organizmaya rastlanılmamıştır (Tablo 2).

3. istasyonda kaydedilen türlerden en önemlisi Rotifera'dan $P$. dolichoptera' dır . Tür 10 ay boyunca kaydedilmiştir. S. oblonga 7 ay boyunca tespit edilmiştir. Cladocera dan ise Bosmina longirostris olup Copepoda'dan ise sadece Cyclops vicinus kaydedilmiştir (Tablo 3).

4.istasyonda kaydedilen türlerden en önemlisi Rotifera'dan Polyarthra dolichoptera dir. $\mathrm{Bu}$ tür 9 ay süresince kaydedilmiştir. Asplanchna priodonta bu türü 6 ay ortaya çıkarak takip etmiştir. Cladocera'dan ise Bosmina longirostris, Alona guttata, Chydorus sphaericus aynı sıklıkla bulunmuş olup Copepoda'dan ise sadece Cyclops vicinus kaydedilmiştir. Rotifer tür sayısı açısından en zengin istasyon (8 tür) 1. istasyondur. Bunu 7 tür ile 2 . istasyon izlemektedir. Cladocera tür sayıs1 bakımından en zengin istasyon 1.istasyon'dur. Copepoda grubu tür sayısı ise tüm istasyonlarda eşit bir şekilde dağılım göstermiştir (Tablo 4).

Baraj Gölü'ndeki zooplankton dağılımına bakıldığında 4 istasyonda da Rotifera grubuna ait türlerin fazla olduğu görülmektedir (Şekil 2). Tatlı sularda Rotiferler zooplanktonik gruplar arasinda dominanttırlar (Saksena 1987). Tüm zooplankton içinde Rotifera türleri 1.istasyonda \% 84, 2.istasyonda $\% 79$, 3.istasyonda $\% 75$, 4.istasyonda $\% 70$ lik oranlara sahiplerdir.

Baraj Gölü’nde en düşük su sicaklığı 1.istasyonda Ocak ayında $3,8{ }^{\circ} \mathrm{C}$ en yüksek su sicaklığ 1 4.istasyonda $27,1{ }^{\circ} \mathrm{C}$ olarak Temmuz ayında, en düşük $\mathrm{pH}$ değeri 1.istasyon Eylül ayında 8,1 iken en yüksek değeri 1.istasyonda Şubat ayında 9,6 olarak ölçülmüştür. Çözünmüş oksijen değeri 1.istasyon Haziran ayında en düşük $6,4(\mathrm{mg} / \mathrm{l})$ en yüksek değeri 2. İstasyon Ocak ayında 12,2 (mg/l), elektriksel iletkenlik 2.istasyon Ocak ayında 223 $(\mu \mathrm{S} / \mathrm{cm})$ iken en yükssek değeri 2.istasyonda Ağustos ayında $422(\mu \mathrm{S} / \mathrm{cm})$ olarak, Seki disk en yüksek değeri 4.istasyonda Kasım ayında 5,5 (m) olarak değerlendirilmiştir(Tablo5). 


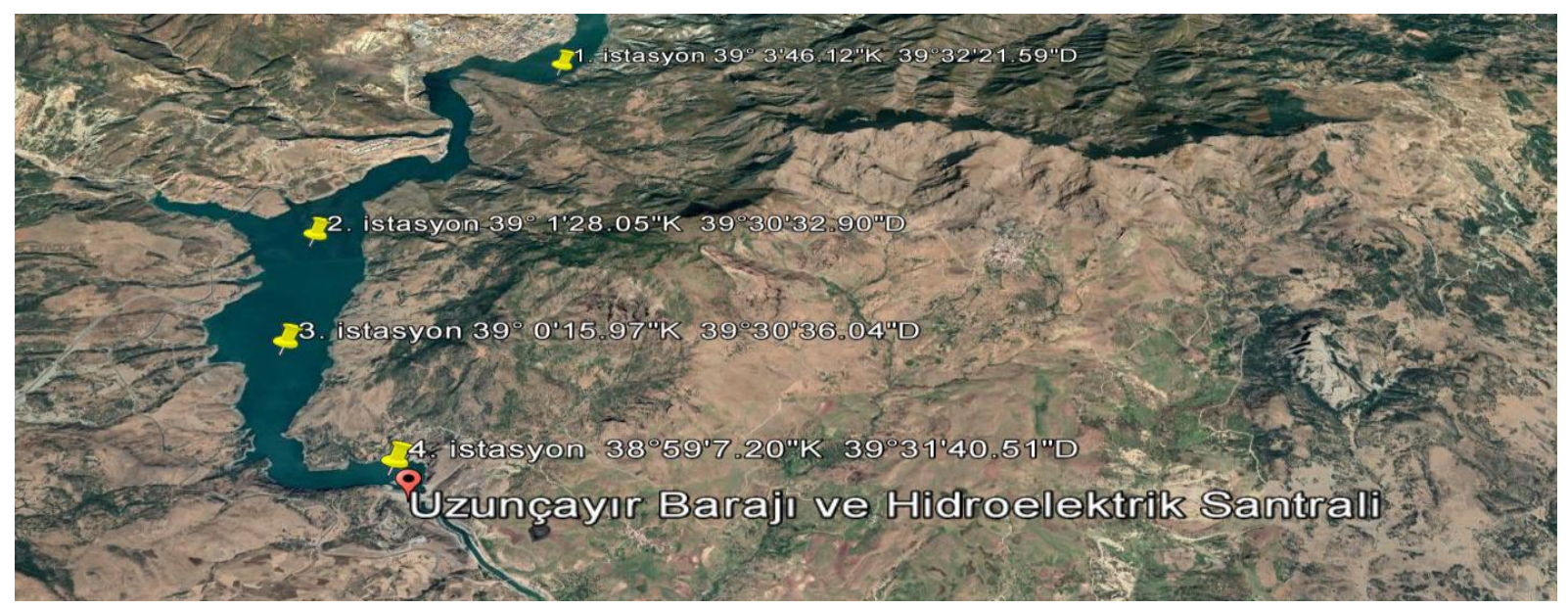

Şekil 1. Uzunçayır Baraj Gölü ve Örnekleme İstasyonları

Tablo 1. Uzunçayır Baraj Gölü’nde Kaydedilen Zooplankton Türlerinin 1. İstasyonda Aylara Göre Dağglımı

\begin{tabular}{|l|l|l|l|l|l|l|l|l|l|l|l|l|}
\hline & $\mathrm{N}$ & $\mathrm{M}$ & $\mathrm{H}$ & $\mathrm{T}$ & $\mathrm{A}$ & $\mathrm{E}$ & $\mathrm{E}$ & $\mathrm{K}$ & $\mathrm{A}$ & $\mathrm{O}$ & $\mathrm{S}$ & $\mathrm{M}$ \\
\hline Rotifera & & & & & & & & & & & & \\
\hline Ascomorpha ecaudis & - & - & - & - & - & - & + & - & - & - & - & - \\
\hline A. saltans & - & - & - & + & - & - & - & - & - & - & - & - \\
\hline Asplanchna priodonta & - & - & + & - & + & + & + & + & + & + & - & + \\
\hline A.sieboldi & - & - & - & - & - & - & + & - & - & - & - & - \\
\hline A.girodi & - & - & - & - & - & - & - & + & - & - & - & - \\
\hline Cephalodella gibba & - & - & + & - & - & - & - & - & - & - & - & + \\
\hline Colurella colurus & - & + & - & - & - & - & - & - & - & - & - & - \\
\hline Euchlanis dilatata & - & - & - & - & - & - & - & - & - & - & - & + \\
\hline Filinia longiseta & - & - & + & - & + & - & - & - & - & - & - & - \\
\hline Gastropus stylifer & - & - & - & - & - & - & - & - & - & - & + & - \\
\hline Keratella cochlearis & - & - & + & - & - & - & - & + & + & + & - & + \\
\hline K.quadrata & + & + & - & - & - & - & - & - & - & - & - & + \\
\hline Synchaeta oblonga & - & - & + & + & - & - & - & - & - & + & - & + \\
\hline S. pectinata & - & - & + & - & - & - & + & - & - & - & - & - \\
\hline Lecane lunaris & - & - & - & - & - & - & - & - & - & - & + & - \\
\hline Lepadella ovalis & - & - & - & - & - & - & - & - & - & - & + & - \\
\hline Notholca acuminata & - & - & - & - & - & - & - & - & - & - & - & + \\
\hline N. squamula & - & - & - & - & - & - & - & - & - & - & + & - \\
\hline Polyarthra dolichoptera & - & - & + & + & + & - & + & + & + & + & - & + \\
\hline Proales decipiens & - & - & - & - & - & - & - & + & - & - & - & - \\
\hline Trichocerca capucina & - & - & + & - & - & - & - & - & - & - & - & - \\
\hline Trichotria tetractis & - & - & - & - & - & - & - & - & - & - & + & - \\
\hline Toplam (taxa) & $\mathbf{1}$ & $\mathbf{2}$ & $\mathbf{8}$ & $\mathbf{3}$ & $\mathbf{3}$ & $\mathbf{1}$ & $\mathbf{5}$ & $\mathbf{5}$ & $\mathbf{3}$ & $\mathbf{4}$ & $\mathbf{4}$ & $\mathbf{8}$ \\
\hline Cladocera & & & & & & & & & & & & \\
\hline Bosmina longirostris & - & - & - & - & - & - & + & - & - & - & - & - \\
\hline Daphnia cucullata & - & - & - & - & - & - & + & - & - & - & - & - \\
\hline Toplam (taxa) & - & - & - & - & - & - & $\mathbf{2}$ & - & - & - & - & - \\
\hline
\end{tabular}




\begin{tabular}{|l|l|l|l|l|l|l|l|l|l|l|l|l|}
\hline Copepoda & & & & & & & & & & & & \\
\hline Acanthocyclops robustus & - & - & - & - & - & - & - & - & - & + & + & - \\
\hline Cyclops vicinus & - & - & - & - & - & - & - & + & - & - & - & - \\
\hline Toplam (taxa) & - & - & - & - & - & - & - & 1 & - & - & - & - \\
\hline Toplam zooplankton(taxa) & $\mathbf{1}$ & $\mathbf{2}$ & $\mathbf{8}$ & $\mathbf{3}$ & $\mathbf{3}$ & $\mathbf{1}$ & $\mathbf{7}$ & $\mathbf{6}$ & $\mathbf{3}$ & $\mathbf{4}$ & $\mathbf{4}$ & $\mathbf{8}$ \\
\hline
\end{tabular}

Tablo 2. Uzunçayır Baraj Gölü’nde Kaydedilen Zooplankton Türlerinin 2. İstasyonda Aylara Göre Dağılımı

\begin{tabular}{|c|c|c|c|c|c|c|c|c|c|c|c|c|}
\hline & $\mathrm{N}$ & M & $\mathrm{H}$ & $\mathrm{T}$ & $\mathrm{A}$ & $\mathrm{E}$ & $\mathrm{E}$ & $\mathrm{K}$ & $\mathrm{A}$ & $\mathrm{O}$ & Ş & $\mathrm{M}$ \\
\hline \multicolumn{13}{|l|}{ Rotifera } \\
\hline Ascomorpha ecaudis & - & - & - & + & - & + & - & - & + & - & - & - \\
\hline A. saltans & - & - & - & + & - & - & - & - & - & - & - & - \\
\hline Asplanchna priodonta & - & - & - & - & - & - & - & + & + & - & - & - \\
\hline A.sieboldi & - & - & - & - & - & + & - & - & - & - & - & - \\
\hline A.girodi & - & - & - & - & - & - & - & + & + & - & - & - \\
\hline Cephalodella gibba & + & - & - & - & - & - & - & - & - & - & + & + \\
\hline Filinia longiseta & - & - & - & - & - & + & - & - & - & - & - & - \\
\hline Filinia terminalis & - & - & - & - & - & - & - & + & - & - & - & - \\
\hline Keratella cochlearis & - & + & - & + & - & - & + & + & + & + & - & - \\
\hline K.quadrata & - & - & - & - & - & - & - & - & - & - & + & - \\
\hline Synchaeta oblonga & - & - & - & - & - & - & + & - & + & + & + & - \\
\hline S. pectinata & - & - & - & - & - & - & + & - & + & - & - & - \\
\hline Lecane furcata & - & - & - & - & - & - & - & - & - & - & + & - \\
\hline Lecane luna & - & - & - & - & + & - & + & - & - & - & - & - \\
\hline Lecane lunaris & + & - & - & - & - & - & - & - & - & - & - & - \\
\hline Lecane stenroosi & - & - & - & - & - & - & - & + & - & - & - & - \\
\hline Lepadella ovalis & - & - & - & - & - & - & - & - & - & - & - & + \\
\hline N. squamula & - & - & - & - & - & - & - & + & - & - & - & - \\
\hline Polyarthra dolichoptera & - & - & + & + & + & + & + & - & - & + & + & + \\
\hline Proales decipiens & - & - & - & - & - & - & + & - & - & - & - & - \\
\hline Trichocerca capucina & - & - & - & - & - & - & - & + & + & - & - & - \\
\hline Trichocerca similis & - & - & - & - & - & - & + & - & - & - & - & - \\
\hline Toplam (taxa) & 2 & 1 & 1 & 4 & 2 & 4 & 7 & 7 & 7 & 3 & 5 & 3 \\
\hline \multicolumn{13}{|l|}{ Cladocera } \\
\hline Bosmina longirostris & + & + & - & - & - & - & - & + & - & - & - & - \\
\hline Cyhdorus sphaericus & - & - & - & - & - & + & - & + & - & - & - & - \\
\hline Daphnia cucullata & - & - & - & - & - & - & - & - & + & - & - & - \\
\hline Moina macrocopa & - & - & - & - & - & - & - & + & - & - & - & - \\
\hline Toplam(taxa) & 1 & 1 & - & - & - & 1 & - & 3 & 1 & - & - & - \\
\hline \multicolumn{13}{|l|}{ Copepoda } \\
\hline Acanthodiaptomus denticornis & - & - & - & - & - & - & - & + & - & - & - & - \\
\hline Cyclops vicinus & - & - & - & - & - & - & + & - & - & - & - & - \\
\hline Toplam (taxa) & - & - & - & - & - & - & 1 & 1 & - & - & - & - \\
\hline Toplam zooplankton(taxa) & 3 & 2 & 1 & 4 & 2 & 4 & 8 & 11 & 8 & 3 & 5 & 3 \\
\hline
\end{tabular}


Tablo 3. Uzunçayır Baraj Gölü’nde Kaydedilen Zooplankton Türlerinin 3. İstasyonda Aylara Göre Dağılımı

\begin{tabular}{|l|l|l|l|l|l|l|l|l|l|l|l|l|}
\hline & $\mathrm{N}$ & $\mathrm{M}$ & $\mathrm{H}$ & $\mathrm{T}$ & $\mathrm{A}$ & $\mathrm{E}$ & $\mathrm{E}$ & $\mathrm{K}$ & $\mathrm{A}$ & $\mathrm{O}$ & $\mathrm{S}$ & $\mathrm{M}$ \\
\hline Rotifera & & & & & & & & & & & & \\
\hline Asplanchna priodonta & + & - & - & - & - & - & - & + & - & - & - & + \\
\hline A.sieboldi & + & - & - & - & + & - & - & - & - & - & - & - \\
\hline A.girodi & - & - & - & - & - & - & - & - & - & - & - & + \\
\hline Cephalodella gibba & - & + & - & - & - & - & - & - & - & - & - & - \\
\hline Euchlanis dilatata & - & - & - & - & - & - & - & - & + & - & - & - \\
\hline Keratella cochlearis & - & - & + & - & - & - & - & - & - & - & - & + \\
\hline Synchaeta oblonga & + & - & + & - & - & - & + & + & + & - & + & + \\
\hline S. pectinata & + & - & - & + & - & - & - & + & - & - & + & + \\
\hline N. squamula & - & - & - & - & - & - & - & - & - & - & + & - \\
\hline Notommata glyphura & - & - & - & - & - & - & - & - & - & - & - & + \\
\hline Polyarthra dolichoptera & + & + & + & + & + & + & + & + & - & - & + & + \\
\hline Trichocerca capucina & - & - & - & - & - & + & + & - & - & - & - & - \\
\hline Toplam (taxa) & $\mathbf{5}$ & $\mathbf{2}$ & $\mathbf{3}$ & $\mathbf{2}$ & $\mathbf{2}$ & $\mathbf{2}$ & $\mathbf{3}$ & $\mathbf{3}$ & $\mathbf{2}$ & - & $\mathbf{4}$ & $\mathbf{7}$ \\
\hline Cladocera & & & & & & & & & & & & \\
\hline Alona guttata & - & - & - & - & - & - & + & - & - & - & - & - \\
\hline Bosmina longirostris & + & - & - & - & - & - & - & - & + & - & - & + \\
\hline Cyhdorus sphaericus & - & - & - & - & - & - & - & - & - & + & + & - \\
\hline Toplam (taxa) & 1 & - & - & - & - & - & 1 & - & 1 & 1 & 1 & 1 \\
\hline Copepoda & & & & & & & & & & & & \\
\hline Cyclops vicinus & - & - & - & - & - & - & + & + & - & + & - & + \\
\hline Toplam (taxa) & 1 & - & - & - & - & - & 1 & - & 1 & 1 & 1 & 1 \\
\hline Toplam zooplankton (taxa) & $\mathbf{7}$ & $\mathbf{2}$ & $\mathbf{3}$ & $\mathbf{2}$ & $\mathbf{2}$ & $\mathbf{2}$ & $\mathbf{5}$ & $\mathbf{3}$ & $\mathbf{4}$ & $\mathbf{2}$ & $\mathbf{6}$ & $\mathbf{9}$ \\
\hline
\end{tabular}

Tablo 4. Uzunçayır Baraj Gölü’nde Kaydedilen Zooplankton Türlerinin 4. İstasyonda Aylara Göre Dağglımı

\begin{tabular}{|l|l|l|l|l|l|l|l|l|l|l|l|l|}
\hline & $\mathrm{N}$ & $\mathrm{M}$ & $\mathrm{H}$ & $\mathrm{T}$ & $\mathrm{A}$ & $\mathrm{E}$ & $\mathrm{E}$ & $\mathrm{K}$ & $\mathrm{A}$ & $\mathrm{O}$ & $\mathrm{S}$ & $\mathrm{M}$ \\
\hline Rotifera & & & & & & & & & & & & \\
\hline Ascomorpha saltans & - & - & + & - & - & - & - & - & - & - & - & - \\
\hline Asplanchna priodonta & + & - & - & - & - & - & + & + & - & + & + & + \\
\hline A.sieboldi & - & - & - & - & - & - & - & - & - & - & + & - \\
\hline Cephalodella gibba & - & + & - & - & - & - & - & - & - & - & - & - \\
\hline Keratella cochlearis & - & + & - & - & - & - & + & - & - & + & + & + \\
\hline Keratella quadrata & - & - & - & - & - & - & - & - & - & + & - & - \\
\hline Lecane lunaris & - & - & - & - & - & - & - & - & - & - & - & + \\
\hline Synchaeta oblonga & + & + & - & - & - & - & - & - & + & - & + & + \\
\hline S. pectinata & + & - & + & - & - & - & + & + & - & - & + & + \\
\hline Notommata glyphura & - & - & + & - & - & - & - & - & - & - & - & + \\
\hline Polyarthra dolichoptera & + & + & - & + & + & - & + & + & - & + & + & + \\
\hline Trichocerca capucina & - & - & - & - & + & - & - & - & - & - & - & - \\
\hline Toplam (taxa) & $\mathbf{4}$ & $\mathbf{4}$ & $\mathbf{3}$ & $\mathbf{1}$ & $\mathbf{2}$ & - & $\mathbf{4}$ & $\mathbf{3}$ & $\mathbf{1}$ & $\mathbf{4}$ & $\mathbf{6}$ & $\mathbf{7}$ \\
\hline Cladocera & & & & & & & & & & & & \\
\hline
\end{tabular}


Research article/Araştırma makalesi

DOI:10.29132/ijpas.938647

\begin{tabular}{|l|l|l|l|l|l|l|l|l|l|l|l|l|}
\hline Alona guttata & - & - & - & + & - & + & - & - & - & - & - & - \\
\hline Bosmina longirostris & + & - & - & - & - & - & - & - & - & - & - & + \\
\hline Cyhdorus sphaericus & - & - & - & - & - & - & + & - & - & - & + & - \\
\hline Moina macrocopa & - & - & - & - & + & - & - & - & - & - & - & - \\
\hline Toplam (taxa) & $\mathbf{1}$ & - & - & $\mathbf{1}$ & $\mathbf{1}$ & $\mathbf{1}$ & $\mathbf{1}$ & - & - & - & $\mathbf{1}$ & $\mathbf{1}$ \\
\hline Copepoda & & & & & & & & & & & & \\
\hline Cyclops vicinus & + & - & - & - & - & + & + & + & - & + & - & - \\
\hline Toplam (taxa) & 1 & - & - & - & - & 1 & 1 & 1 & - & 1 & - & - \\
\hline Toplam zooplankton (taxa) & $\mathbf{6}$ & $\mathbf{4}$ & $\mathbf{3}$ & $\mathbf{2}$ & $\mathbf{3}$ & $\mathbf{2}$ & $\mathbf{5}$ & $\mathbf{4}$ & $\mathbf{1}$ & $\mathbf{5}$ & $\mathbf{7}$ & $\mathbf{8}$ \\
\hline
\end{tabular}
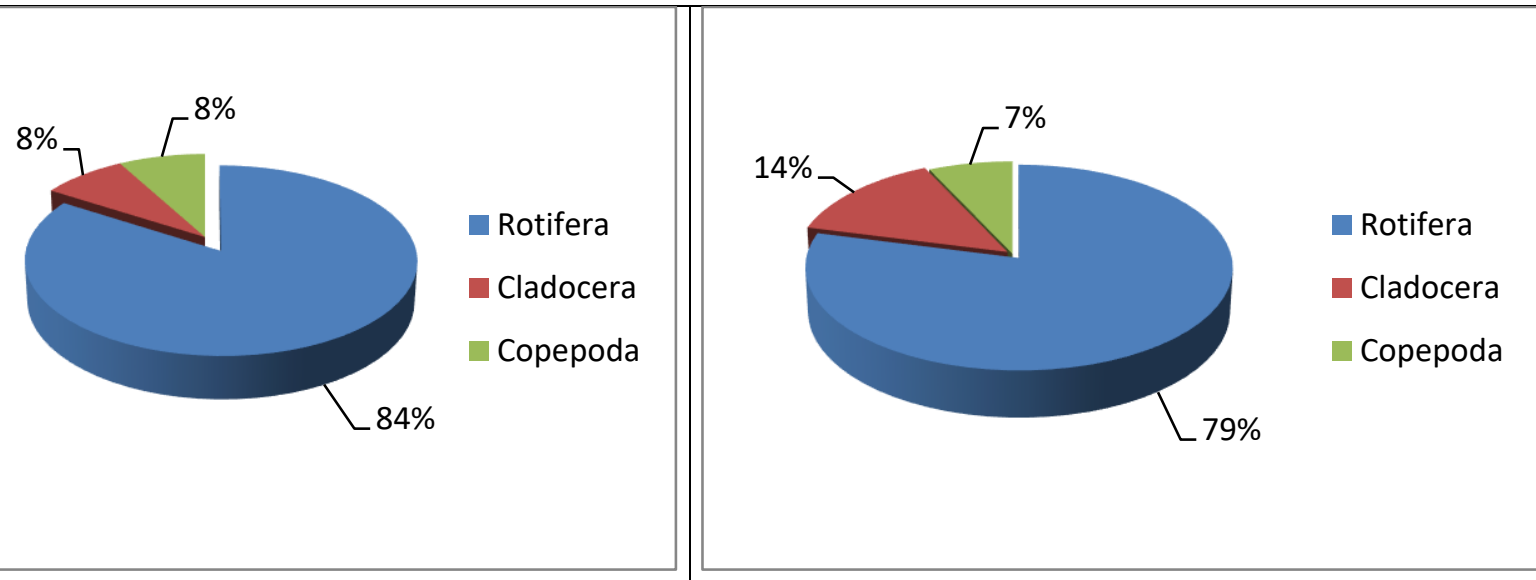

1.istasyon

2.istasyon
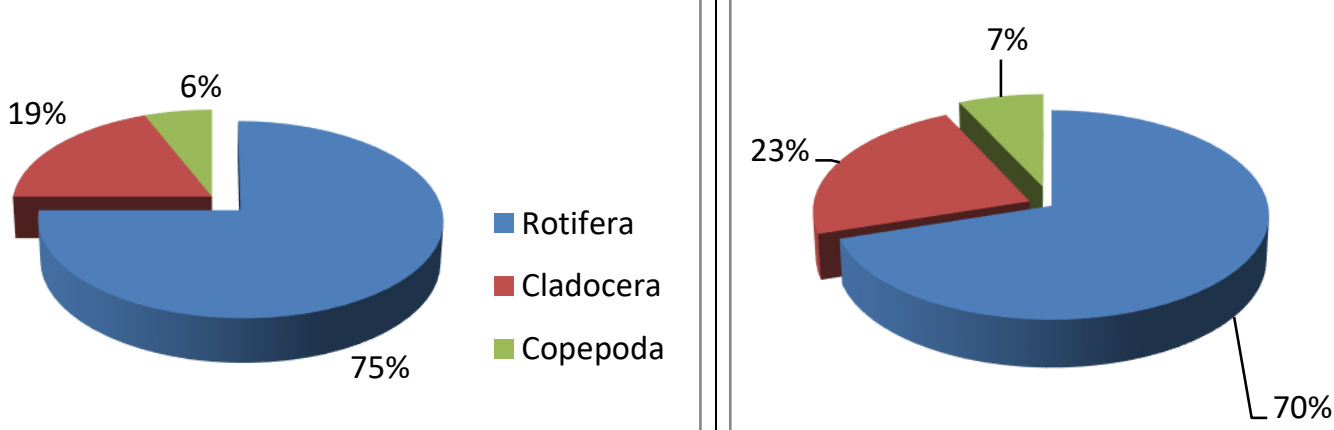

Rotifera

- Cladocera

Copepoda

3.istasyon

4.istasyon

Şekil 2. Uzunçayır Baraj Gölü’nün İstasyonlara Göre Zooplankton Gruplarının Dağılımı 
Tablo 5. Uzunçayır Baraj Gölü’nün sıcaklık, pH, çözünmüş oksijen, elektriksel iletkenlik, seki disk, minimum, maksimum, ortalama değerleri ve standart sapma değerleri’nin aylara göre dağılımı

\begin{tabular}{|c|c|c|c|c|c|c|c|c|c|c|c|c|}
\hline & Ocak & Şubat & Mart & Nisan & Mayıs & Haziran & Temmuz & Ağustos & Eylül & Ekim & Kasım & Aralık \\
\hline 1.ist. & 4,4 & 7,5 & 7,0 & 8,7 & 10,3 & 24,0 & 26,5 & 26,0 & 21,5 & 9,8 & 9,0 & 4,9 \\
\hline 2.ist. & 3,8 & 7,8 & 7,3 & 9,3 & 17,0 & 23,7 & 26,7 & 26,0 & 21,7 & 14,8 & 10,0 & 5,7 \\
\hline 3. ist & 4,2 & 7,6 & 8,1 & 11,3 & 18,0 & 23,2 & 26,0 & 26,0 & 21,6 & 14,8 & 10,2 & 5,9 \\
\hline $4.1 s t$ & 4,3 & 6,5 & 7,0 & 10,7 & 17,7 & 23,7 & 27,1 & 25,3 & 21,6 & 14,8 & 10,1 & 6,0 \\
\hline Min. & 3,8 & 6,5 & 7,0 & 8,7 & 10,3 & 23,2 & 26,0 & 25,3 & 21,5 & 9,8 & 9,0 & 4,9 \\
\hline Mak. & 4,4 & 7,8 & 8,1 & 11,3 & 18,0 & 24,0 & 27,1 & 26,0 & 21,7 & 14,8 & 10,2 & 6,0 \\
\hline Ort. & 4,2 & 7,4 & 7,4 & 10,0 & 15,8 & 23,7 & 26,6 & 25,8 & 21,6 & 13,6 & 9,8 & 5,6 \\
\hline Ss. & 0,3 & 0,6 & 0,5 & 1,2 & 3,7 & 0,3 & 0,5 & 0,4 & 0,1 & 2,5 & 0,6 & 0,5 \\
\hline
\end{tabular}

\section{Sicaklık ( $\left.{ }^{\circ} \mathrm{C}\right)$}

\begin{tabular}{|c|c|c|c|c|c|c|c|c|c|c|c|c|}
\hline & Ocak & Şubat & Mart & Nisan & Mayıs & Haziran & Temmuz & Ağustos & Eylül & Ekim & Kasım & Aralık \\
\hline 1.ist. & 8,6 & 9,6 & 9,4 & 9,1 & 8,7 & 8,5 & 8,7 & 8,8 & 8,1 & 7,7 & 9,1 & 9,5 \\
\hline 2.ist. & 8,2 & 9,4 & 8,5 & 8,8 & 8,4 & 8,4 & 8,5 & 8,7 & 8,2 & 7,9 & 9,1 & 8,3 \\
\hline 3.ist & 8,2 & 9,2 & 8,5 & 8,6 & 8,4 & 8,6 & 8,6 & 8,6 & 8,5 & 8,4 & 9,0 & 8,5 \\
\hline 4.ist & 8,5 & 9,6 & 8,4 & 8,6 & 8,4 & 8,6 & 8,6 & 8,7 & 8,5 & 8,4 & 9,1 & 8,4 \\
\hline Min. & 8,2 & 9,2 & 8,4 & 8,6 & 8,4 & 8,4 & 8,5 & 8,6 & 8,1 & 7,7 & 9,0 & 8,3 \\
\hline Mak. & 8,6 & 9,6 & 9,4 & 9,1 & 8,7 & 8,6 & 8,7 & 8,8 & 8,5 & 8,4 & 9,1 & 9,5 \\
\hline Ort. & 8,4 & 9,5 & 8,7 & 8,8 & 8,5 & 8,5 & 8,6 & 8,7 & 8,3 & 8,1 & 9,1 & 8,6 \\
\hline Ss. & 0,2 & 0,2 & 0,5 & 0,2 & 0,1 & 0,1 & 0,1 & 0,1 & 0,2 & 0,4 & 0,1 & 0,6 \\
\hline
\end{tabular}

$\mathrm{pH}$ 


\begin{tabular}{|l|l|l|l|l|l|l|l|l|l|l|l|l|}
\hline & Ocak & Şubat & Mart & Nisan & May1s & Haziran & Temmuz & Ağustos & Eylül & Ekim & Kasım & Aralık \\
\hline 1. ist. & 13,8 & 11,4 & 12,8 & 12,5 & 12,3 & 6,4 & 9,3 & 9,8 & 9,9 & 11,5 & 11,3 & 13,0 \\
\hline 2.ist. & 12,2 & 11,8 & 12,5 & 11,8 & 10,7 & 7,4 & 10,3 & 10,5 & 9,9 & 10,8 & 10,5 & 12,1 \\
\hline 3.ist & 13,3 & 11,4 & 12,5 & 11,5 & 10,8 & 8,4 & 9,8 & 10,0 & 9,9 & 9,9 & 10,2 & 12,0 \\
\hline 4.ist & 11,7 & 11,8 & 12,6 & 12,5 & 11,0 & 7,8 & 9,0 & 10,7 & 9,8 & 9,2 & 10,7 & 9,8 \\
\hline Min. & 11,7 & 11,4 & 12,5 & 11,5 & 10,7 & 6,4 & 9,0 & 9,8 & 9,8 & 9,2 & 10,2 & 9,8 \\
\hline Mak. & 12,2 & 11,8 & 12,8 & 12,5 & 12,3 & 8,4 & 10,3 & 10,7 & 9,9 & 11,5 & 11,3 & 13,0 \\
\hline Ort. & 13,2 & 11,6 & 12,6 & 12,1 & 11,2 & 7,5 & 9,6 & 10,3 & 9,9 & 10,4 & 10,7 & 11,7 \\
\hline Ss & 1,1 & 0,2 & 0,1 & 0,5 & 0,7 & 0,8 & 0,5 & 0,4 & 0,1 & 1,0 & 0,5 & 1,4 \\
\hline
\end{tabular}

Çözünmüş Oksijen (mg/l)

\begin{tabular}{|c|c|c|c|c|c|c|c|c|c|c|c|c|}
\hline & Ocak & Şubat & Mart & Nisan & Mayıs & Haziran & Temmuz & Ağustos & Eylül & Ekim & Kasım & Aralık \\
\hline 1. ist. & 2 & 0,7 & 0,4 & 0 & 0,6 & 1,1 & 2,6 & 1,6 & 1,15 & 1,5 & 2,5 & 1,5 \\
\hline 2.ist. & 3 & 0,7 & 0,5 & 0 & 1 & 1,1 & 3,3 & 2 & 2,3 & 2,7 & 4,3 & 5 \\
\hline 3. ist. & 4,4 & 1,4 & 0,6 & 1 & 1,9 & 1,5 & 3,3 & 1,7 & 3 & 3,4 & 5,3 & 5,5 \\
\hline 4. ist. & 3,9 & 3 & 0,8 & 1,4 & 1,8 & 2 & 2,9 & 2,1 & 2,8 & 3,4 & 5,5 & 5 \\
\hline Min. & 2 & 0,7 & 0,4 & 0 & 0,6 & 1,1 & 2,6 & 1,6 & 1,15 & 1,5 & 2,5 & 1,5 \\
\hline Mak. & 4,4 & 3 & 0,8 & 1,4 & 1,9 & 2 & 3,3 & 2,1 & 3 & 3,4 & 5,5 & 5,5 \\
\hline Ort. & 3,325 & 1,45 & 0,575 & 0,6 & 1,325 & 1,425 & 3,025 & 1,85 & 2,3125 & 2,75 & 4,4 & 4,25 \\
\hline Ss & 1,1 & 1,1 & 0,1 & 0,7 & 0,6 & 0,4 & 0,3 & 0,2 & 0,8 & 0,9 & 1,3 & 1,8 \\
\hline
\end{tabular}

\section{Seki Disk Değerleri (m)}




\begin{tabular}{|c|c|c|c|c|c|c|c|c|c|c|c|c|}
\hline & Ocak & Şubat & Mart & Nisan & Mayı & Haziran & Temmuz & Ağustos & Eylül & Ekim & Kasım & Aralık \\
\hline 1.ist. & 234 & 239 & 227 & 281 & 283 & 368 & 413 & 417 & 295 & 262 & 251 & 233 \\
\hline 2.ist. & 223 & 247 & 230 & 285 & 353 & 366 & 410 & 422 & 314 & 292 & 261 & 239 \\
\hline 3.ist. & 228 & 249 & 234 & 312 & 352 & 363 & 399 & 416 & 299 & 290 & 263 & 239 \\
\hline 4.ist. & 230 & 239 & 227 & 313 & 343 & 369 & 399 & 407 & 297 & 287 & 261 & 241 \\
\hline Min. & 223 & 239 & 227 & 281 & 283 & 363 & 399 & 407 & 295 & 262 & 251 & 233 \\
\hline Mak. & 234 & 249 & 234 & 313 & 353 & 369 & 413 & 422 & 314 & 292 & 263 & 241 \\
\hline Ort. & 229 & 244 & 229 & 298 & 333 & 366 & 405 & 415 & 301 & 283 & 259 & 238 \\
\hline Ss & 4 & 5 & 3 & 17 & 33 & 3 & 8 & 6 & 9 & 14 & 5 & 3 \\
\hline
\end{tabular}

Uzunçayır Baraj Gölü'nde daha önce yapılan çalışmada 15 Rotifera, 6 Cladocera ve 2 Copepoda teşhis edilmiştir (Saler vd. 2014). Bu çalışmada ise 28 Rotifera, 5 Cladocera ve 3 Copepoda türü bulunmuştur. Güncel çalışmada zooplankton türlerinin fazla olması örnekleme istasyonlarının fazla olması ile ilişkilendirilebilir. Uzunçayır Baraj Gölü'nün üzerinde kurulduğu Munzur Nehri'nde yapılan zooplankton faunası araştırmasında toplam 11 tür saptanmıştır (Saler 2011). Bu tür çeşitliliği farkı Munzur Nehri'nin çok hızlı akması ve daha soğuk olmasından kaynaklanabilir.

Peri Çayı'nda (Saler vd. 2011a), Rotiferadan, 10 tür Cladocera'dan 3 tür, Copepoda'dan, 2 tür, Pülümür Çayı'nda (Saler ve Haykır 2011), Rotiferadan 15 tür, Cladocera'dan 4 tür, Copepoda'dan 2 tür Murat Nehri'nde (Saler ve Haykır 2014), Rotiferadan 25 tür, Cladocera'dan 6 tür Copepoda'dan 2 tür tespit edilmiştir. Yapılmış olan bu çalışmalarda Rotifera'nın baskın olması bu çalışma ile benzerlik göstermektedir.

Mart 2010-Şubat 2011 de Uzunçayır Baraj gölü'nde yapılan çalışmada Rotifera'dan; A. saltans, A. priodonta, A. sieboldi, C. gibba, K. cochlearis, $K$. quadrata, L. luna, L. ovalis, N. acuminata, N. squamula, $S$. pectinata, $P$. dolichoptera, $T$. capucina, $T$. tetractis Cladocera'dan; $B$. longirostris, C. sphaericus, Copepoda'dan; A. denticornis, C. vicinus bu çalışma ile ortak çıkan türlerdir (Saler vd. 2014).
Aynı bölgede bulunan, Seli Çayı'nın rotiferlerinin araştırıldığ çalışmada tür çeşitliliğine bakılacak olursa ilkbaharda rotiferlerin tür çeşitliliğinin en fazla olduğu, Uzunçayır'da rotiferlerden en fazla türün Brachionidae'ye ait olduğu görülmüsstür. En fazla tür sayısı ilkbahar ve sonbahar mevsimlerinde gözlemlenmiş olup bu Baraj Gölü'nde yapılan çalışma ile paralellik göstermektedir (İpek ve Saler 2008).

Seli Çayı Cladocera ve Copepoda faunası ile ilgili olan çalışmada en fazla görülen organizmalar B.longirostris ile C.vicinus olup, bizim çalışmamızla ile bu sonuçlar örtüşmektedir (Saler ve İpek 2009).

Aynı bölgede bulunan Tahar Çayı zooplanktonun tür çeşitliliği bakımından rotiferlerin diğer zooplanktonlara göre değişiklik gösterdiği, aynı zamanda her ay en fazla tür çeşitliliğine sahip olan grubun Rotifera olduğu görülmüştür (Öcalan ve Saler 2016).

Kürk Çayı ve Çalgan Deresi'nde yapılan çalışmalarda da bahar aylarında yoğun olarak, en az ise kış mevsiminde rotiferlerin ortaya çıktıkları ifade edilmiştir. $\mathrm{Bu}$ veriler çalışmanın sonuçları ile değerlendirildiğinde benzerlik göstermektedir (Saler vd. 2011b; Baysal ve Saler 2014).

Zooplanktonu etkileyen en önemli faktörler su sıcaklığ1 ve çözünmüş oksijendir. Su sıcaklığ akuatik canlıların sucul yaşamdaki kimyasal ve biyolojik aktivitesini yöneten en önemli parametrelerden biridir (Buyurgan vd. 2010,Saler vd. 2015). Zooplankton yaşam döngüsü için önemli 
olan $\mathrm{pH}$ seviyesinin alkali sınırı 8,5'tir (Berzins ve Pejler 1987). Bu çalışmada alkali sınır 8,5 değerinin üzerinde kaydedilmiştir. Buna göre çalışmada kaydedilen zooplankton türlerinin bu $\mathrm{pH}$ değerlerine uyum gösterdiği söylenebilir.

Çözünmüş oksijen miktarları, sıcaklığa ve göllerin trofik seviyesine göre değişim gösterir (Moss 1981). Rotifera türlerinin çoğu yüksek oksijen toleransına sahiptir, düşük oksijen içeriğine sahip suların zooplankton gelişimini, üremesini ve dağılımını etkilediğini ve tatlı suda $5 \mathrm{mgL}^{-1}$ in altındaki çözünmüş oksijen seviyelerinin zooplankton gelişimini engellediği belirtilmiştir (Devol 1981). Bu çalışmada her örneklemede çözünmüş oksijen seviyesi 5mg / L'nin üzerinde belirlenmiştir. $\mathrm{Bu}$ habitatın, çözünmüş oksijen seviyesine göre zooplankton yaşamı için uygun olduğu görülmektedir.

İletkenlik veya elektriki iletkenlik; $1 \mathrm{~cm}^{2}$ alanda, $1 \mathrm{~cm}$ aralıklı duran iki platin elektrot arasındaki direncin ölçümü olarak ifade edilebilir yada doğal sularda, kabaca sudaki çözünmüş maddelerin toplamıdır (Tanyolaç 1993). Yağış miktarıyla birlikte jeolojik yapıya bağlı olarak farklılık gösteren iletkenlik sudaki besin tuzlarından etkilenmez (Temponeras vd. 2000). Elektriksel iletkenlik tatlı sularda $10-1000 \mu \mathrm{S} / \mathrm{cm}$ arasinda değișiklik göstermektedir. Su ürünleri standartları ve yüzeysel su kaynaklarının kirlenmeye karşı korunması hakkındaki protokolde belirtilen elektriksel iletkenlik değeri (150-500 $\mu \mathrm{S} / \mathrm{cm})$ arasında yer almaktadır (Uslu ve Türkman 1987). Bu çalışmada ise 223-422 $\mu \mathrm{S} / \mathrm{cm}$ değerleri arasında değişmektedir ve bu değerlerin tüm istasyon ve aylarda mevcut standartlar arasında olduğu gözlenmiștir.

Trofik sınıflandırma sistemi için OECD seki disk sınır değerlerine göre $(0,8-1,5 \mathrm{~m})$ aralığındaki göller ötrofik, (1,4 - 2,4 m) aralığındaki göller mezotrofik, $(3,6-5,9 \mathrm{~m})$ aralığındaki göller ise oligotrofik olarak sınıflandırılmaktadır (Ryding ve Rast 1989). Bu değerlere göre Uzunçayır Baraj Gölü oligotrofik grupta değerlendirilmektedir.

İlkbahar mevsiminde seki diski değerinin az olmasının nedeni yağışların artması ile birlikte akarsuların baraj gölüne sediment taşıması ile seki disk değerinin düşük olduğu söylenebilir. Uzunçayır baraj Gölünde yapılan bir başka çalışmada bu bilgiyi destekler niteliktedir (Kutlu vd. 2017).

Saler vd. 2014 yaptıkları çalışmada su kalite parametrelerinden en düşük ve en yüksek sıcaklık $\left(8,6-20,1^{\circ} \mathrm{C}\right)$, çözünmüş oksijen $(4,6-10,1 \mathrm{mg} / \mathrm{l})$ ve $\mathrm{pH}(6,8-8,1)$ değerlendirirken bu çalıșmada ise bunlara ek olarak elektriksel iletkenlik ve seki diski değerleri de değerlendirilmiştir.

Bazı literatürlerde $\mathrm{pH}$, çözünmüş oksijen ve sicaklığın örnekleme yapılan tüm noktalarında I. sınıf su kalitesinde olduğu bulunmuştur. Bu değerler ile kıyaslandığında bizim bulgularımızla bu değerlerin örtüştüğü görülmektedir (Erkil vd. 2015).

Uzunçayır Barajı karasal bir tatlı su gölü olup iyi durumda olduğu öngörülebilecek bir su kalitesine sahip olduğu, kirlilik düzeyinin yüksek düzeyde olmadığ1 ve zooplankton yaşamı için uygun ortam koşullarına sahip olduğu da söylenebilir.

\section{TEŞEKKÜR}

Bu çalışma TAGEM/HAYSÜD/2017/A-11/P-03/1

nolu proje tarafindan desteklenmiştir

\section{ÇIKAR ÇATIŞMASI BEYANI}

Yazarlar bu makale ile ilgili herhangi bir çıkar çatışması bildirmemektedir.

\section{ARASTIRMA VE YAYIN ETIĞİ BEYANI}

Yazarlar bu çalışmanın araştırma ve yayın etiğine uygun olduğunu beyan eder.

\section{KAYNAKLAR}

Baysal, N. ve Saler, S. (2014). Çalgan Deresi Elazığ Zooplanktonu. Firat Üniversitesi Fen Bilimleri Dergisi, 26(1): 1-7.

Berzins, B. ve Pejler, B. (1987). Rotifer occurrence in relation to $\mathrm{pH}$, Hydrobiologia 1987; 147: 107-116

Bidder, MD. (1981). Some consideration on the geographical distribution of Rotifers. Hydrobiol., 85: 209-255 p

Boztuğ, D. Dere, T. Tayhan, N. Yıldırım, N. Danabaş, D. Cikcikoğlu Yıldırım N. Öztüfekçi Önal, A. Danabaş, S. Ergin, C. Uslu, G. ve Ünlü, E. (2012). Uzunçayır Baraj Gölü (Tunceli) Fiziko-Kimyasal Özellikleri ve $\mathrm{Su}$ Kalitesinin Değerlendirilmesi. Adıyaman Üniversitesi Fen Bilimleri Dergisi 2 (2): 93-106

Buyurgan, Ö. Altındağ, A. ve Kaya, M. (2010). Zooplankton community structure of Asartepe Dam Lake (Ankara, Turkey). Turk. J Fish. Aquat. Sci. 10: 135-138.

Çoban, MZ. Gündüz, F. Yüksel, F. Demirol, F. Yıldırım, T. ve Kurtoğlu, M. (2013). Uzunçayır Baraj Gölü (Tunceli) Balık Faunası. Yunus Araştırma Bülteni 2013 (2): 35-44. 
Devol, AH.(1981). Vertical distribution of zooplankton respiration in relation to the intense oxygen minimum zones in two British Columbia fjords. Journal of Plankton Research 3: 593-602.

DSI, 2021. Devlet Su İșleri Genel Müdürlüğü. [Erișim Tarihi: 10 Mart 2021]. Erișim Adresi: https: //www.dsi.gov.tr

Dumont, HJ. ve De Ridder, M. (1987). Rotifers from Turkey. Hydrobiologia. 147: 65-73.

Edmondson, WT. (1959). Rotifera in "Fresh Water Biology". Ed. Edmondson W.T. Second edition, University of Washington Seattle.

Einsle U. (1996). Copepoda: Cyclopoida, Genera Cyclops, Megacyclops, Acanthocyclops. Guides to the Identification of the Microinvertebrates of the Continental Waters of the World No.10 SPB Academic Publishing, London, $82 \mathrm{p}$.

Erkil, V. Küçükgül, A. Serdar, O. Aydın, R. ve Otay, T. (2015). Tunceli İli ve Çevresi Tatlı Su Kaynaklarında Suyun Fiziko-Kimyasal Parametreleri ve Nitrojenli Bileşiklerin Mevsimsel Değerleri. Bilim ve Gençlik Dergisi 3(2): 1-11

Gannon, EJ, Stemberger, SR. (1978). Zooplankton as ndicators of Water Quality. Trans Amer. Micros. Soc. 97 (1): 16-35

Grasse, P. (1965). Traite de Zoologie, Anatomie, Systematique, Biologie, Nome IV, Fassicule III, Mason Etc Editeurs Libraires De L"Academie De Medecine Annales de Limnologie 6(2):161-190.

İpek, N. ve Saler, S. (2008). Seli Çayı (Elazığ-Türkiye) Rotifer Faunası ve Bazı Biyoçeşitlilik İndeksleri ile Analizi. E.Ü. Su Ürünleri Dergisi. 25(3):211-215.

Kamburska, L. Moncheva, S. Konsulov, A. Krastev, A. Prodonov, K. (2003). The invasion of Beroe ovata in the Black Sea a warning signal for ecosystem concern. Inst. Oceanogr., Bulgarian Acad. Sci., 4(11): 123p.

Kaya, M. Altındağ, A. (2007). Brachionidae (Rotifera: Monogononta) Species from Turkey. Asian Journal of Animal Sciences, 1, 40-47.

Kolisko, WR. (1974). Planktonic Rotifers Biologyand Taxonomy Biological Station, Lunz of TheAustrian Academy of Science, Stuttgart, 974 s

Koste, W. (1978a). Rotatoria. Überordnung Monogononta. I. Textband, Gebrüderssontrager, Berlin, 650s.

Koste, W. (1978b). Rotatoria. Gebrüder Borntraeger, II. Tafelband, Stuttgart, 234s.
Kutlu, B. Serdar, O. Aydın, R. ve Danabaş, D. (2017). Uzunçayır Baraj Gölü'nün (Tunceli) Carlson İndeksine Göre Trofik Durumunun Belirlenmesi. Yunus Araştırma Bülteni (1): 83-92.

Marneffe, Y. Comblin, S.ve Thome, J. (1998). Ecological water quality assesment of the Bütgenbach lake (Belgium) and its impact on the river Warche using rotifers as bioindicators. Hydrobiol., 387/388: 459$467 \mathrm{p}$.

Michaloudi, E. Zarfdjian, M. ve Econormidis, P. (1997). The zooplankton of Lake Micri Prespa. Hydrobiol., 351: 77-94p

Moss, B. (1981). The Art and Science of Lake Restoration. Springer 581: 15-24.

Negrea, ST. (1983). Fauna Republici Socialiste Romania, Crustacea Cladocera. Academia Republici Socialiste Romania, Bukres, 399 p.

Öcalan, A. ve Saler, S. (2016). Tahar Çayı Tunceli zooplanktonu. Fırat Üniv. Müh. Bil. Dergisi. 28(2): 1-10

Özcan, Eİ. (2019). Pülümür Nehri (Tunceli, Türkiye)'ndeki Barbus lacerta Heckel, 1843'ün Boy-Ağırlık İlişkisi ve Kondisyon Faktörü. NwsaEcological Life Sciences 14(4): 66-73.

Özcan, Eİ. (2020). Pülümür Nehri'nde Yaşayan Acanthobrama $\quad$ marmid Heckel, 1843 Populasyonunun Bazı Büyüme Özelliklerinin Belirlenmesi. Ecological Life Sciences (NWSAELS), 15(4):121-133, DOI: 10.12739/NWSA.2020.15.4.5A0139.

Ryding, SO. ve Rast, W. (1989). The Control of Eutrophication of Lakes and Reservoirs. UNESCO, Man And The Biosphere Series. Vol.1. The Parthenon Publishing Group, New Jersey. 314 pp.

Saksena, ND. (1987). Rotifer as indicators of water quality. Acta Hydroch Hydrobiol., 15: 481-485p

Saler, S. (2011). Zooplankton of Munzur River Tunceli Turkey. Journal of Animal and Veterinary Advances. 10(2): 192-194.

Saler, S. ve İpek, N. (2009). Cladocera and Copepoda (Crustacea) Fauna of Seli Stream (Elazığ-Turkey) Journal of FisheriesSciences.com 3(4): 318-322

Saler, S. ve Haykır, H. (2011). Zooplankton Composition of Pulumur Stream (Tunceli-Turkey), Journal of Animal and Veterinary Advances, 10: 11, 14011403.

Saler, S. Haykır, H. (2014). Murat Nehri’nin (Elazı̆̆-Palu ilçe merkezi sınırları içindeki bölümünde) 
zooplanktonu ve değişimi. Türk Tarım Gıda Bilim ve Teknoloji Dergisi, 2(1): 13-17.

Saler, S. Eroğlu M. ve Haykır H. (2011a). Peri Çayı (Tunceli-Türkiye) zooplanktonu. e-Journal of New WorldSciences Academy, 6, 2, 14-20.

Saler, S. İpek, N. ve Arslan, S. (2011b). Kürk Çayı (Elazığ-Türkiye) Zooplanktonu, Journal of Fisheriessciences.com, 5 (3), 219-225

Saler, S. Haykır, H. ve Baysal, N. (2014). Zooplankton of Uzunçayır Dam Lake (Tunceli-Turkey), Journal of Fisheriessciences.com. 8(1): 1-7.

Saler, S. Bulut, H. Örnekçi, GN. ve Uslu, AA. (2015). Ulaş Gölü (Ulaş-Sivas) Zooplanktonu, International Journal of Pure and Applied Sciences, 1(2): 112121.

Shiganova, T. (2005). Changes in appendicularian Oikopleura dioica abundance caused by invasion of alien ctenophores in the Black Sea. Journ. Mar. Biol. Ass., U.K., 85: 477-494.

Siokou-Frangou, I. Papathanassiou, AE. ve Lepretre Frontier, S. (1998). Zooplankton assemblages and influence of environmental parameters on them in a Mediterranean coastal area. Journ. Plankton Res., 20: 847-870p.

Sladecek, V. (1983). Rotifers as indicators of water quality, Hydrobiologia, 100, 169-201p.

Tanyolaç J. 1993. Limnoloji. Cumhuriyet Üniv. Fen. Fak. Hatipoğlu Yayınevi. Ankara 68.

Temponeras, M. Kristiansen, J. ve Moustaka-Gouni, M. (2000). Seasonal variation in phytoplankton composition and physical-chemical features of the shallow Lake Doirani Macedonia, Greece. Hydrobiologia, 424: 109-122.

Uslu, O. Türkman, A. (1987). Su Kirliliği ve Kontrolü. T.C. Başbakanlık Çevre Genel Müdürlüğü Yayınları. Eğitim Dizisi I, Ankara.

Vidjak, O. Bojanic, N. Kuspilic, G. Marasovic, I. Gladan, NZ. ve Brautovic, I. (2006). Annual variability and trophic relations of the mesozooplankton community in the eutrophicated coastal area (Vranjic Basin, eastern Adriatic Sea). J. Mar. Biol. Ass. U.K., 86: $19-26$

Wallace, R. ve Snell, TW. (1991). Rotifera, ecology and classification of North American Freshwater invertebrates, Academic Press, 187-249p 